\title{
O AUTISMO NO CAMINHO DA PATOLOGIZAÇÃO E MEDICALIZAÇÃO: EFEITOS DA LEI 13.438, DE 26 DE ABRIL DE 2017
}

\author{
Autism in the way of pathologization and medicalization: effects of Law 13.438, of \\ april 26, 2017
}

\author{
Suely Maria Costa Lôbo (UCSal) \\ Informações do artigo \\ Recebido em 20/06/2018 \\ Aceito em 11/07/2018
}

doi>: https://doi.org/10.25247/2447-861X.2019.n246.p83-91

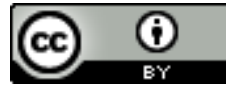

Esta obra está licenciada com uma Licença Creative Commons Atribuição 4.0 Internacional.

\section{Como ser citado (modelo ABNT)}

LÔBO, Suely Maria Costa. O autismo no caminho da patologização e medicalização: efeitos da Lei 13.438, de 26 de abril de 2017. Cadernos do CEAS: Revista Crítica de Humanidades, Salvador, n. 246, jan./abr., p. 83-91, 2019. DOI: https://doi.org/10.25247/2447861X.2019.n246.p83-91

\begin{abstract}
Resumo
Os marcos legais, como a Lei 10.216 e a Portaria 336, do Ministério da Saúde, contribuíram para a garantia de um novo modelo de assistência aos pacientes portadores de transtornos mentais. Leis diferenciadas, para grupos mais vulneráveis, também implementaram novas formas de acesso, dentre elas a Lei 12.764 , para os portadores de autismo. Contudo, recentemente, foi promulgada a Lei 13.438, que engessa os mecanismos diagnósticos para esse transtorno. $O$ objetivo desse artigo é discutir os efeitos clínicos da utilização desse critério diagnóstico, focando na construção da subjetividade da criança que passará por esta avaliação.
\end{abstract}

Palavras-chave: Política de Saúde Mental. Infância e Adolescência, Autismo. Medicalização.

\section{Abstract}

The legal frameworks, such as Law 10.216 and Portaria 336 , of the Ministry of Health, contributed to the guarantee of a new model of care for patients with mental disorders. Differing laws, for more vulnerable groups, also implemented new forms of access, among them Law 12.764, for those with autism. However, Law 13388 has recently been enacted, which enriches the diagnostic mechanisms for this disorder. The objective of this article is to discuss the clinical effects of the use of this diagnostic criterion, focusing on the construction of the subjectivity of the child that will undergo this evaluation.

Keywords: Mental Health Policy. Childhood and Adolescence, Autism. Medication. 


\section{Introdução}

A história da Reforma Psiquiátrica no Brasil perpassa por uma luta de trabalhadores de saúde mental, a exemplo de portadores, familiares, enfim, de uma sociedade que se contrapôs ao modelo hospitalocêntrico que vigorava. Existem vários marcos legais que asseguraram essa mudança. Pode-se citar a Lei 10.216, de 6 de abril de 2001, e a Portaria 336, de 19 de fevereiro de 2002.

A infância e adolescência também se beneficiaram dessas mudanças, além de possuírem algumas leis específicas, pois se considera que algumas patologias e transtornos se instauram e solidificam desde a infância. Com o intuito de firmar uma proteção aos autistas, promulgou-se a Lei 12.764, de 27 de dezembro de 2012. Recentemente, a Lei 13.438, de 26 de abril de 2017 também veio direcionada a esse grupo, mas várias foram as correntes contrárias a sua efetivação.

O objetivo desse artigo é discutir os efeitos da obrigatoriedade dessa investigação, considerando que a criança é um ser em desenvolvimento, e uma prática clínica deve ser construída e efetivada de maneira única, relacionando o funcionamento diferenciado de cada família.

O interesse dessa investigação se deu a partir de uma prática profissional em um Centro de Atenção Psicossocial de Infância e Adolescência (CAPS ia), em conjunto com a realização do Mestrado em Políticas Sociais e Cidadania, da Universidade Católica do Salvador, além da participação no grupo de pesquisa vinculado a esse Programa, o Núcleo de Estudos Interdisciplinares Saúde e Cidadania (NESC).

\section{Marcos legais}

A Reforma Psiquiátrica brasileira materializou-se através da promulgação da Lei 10.216, de 6 de abril de 2001 (BRASIL, 2001). Esta lei dispõe sobre a proteção e os direitos das pessoas portadoras de transtornos mentais e redireciona o modelo assistencial em saúde mental.

Faz parte da Reforma Psiquiátrica a implementação de leis que buscam promover a socialização e a inserção do portador de transtorno mental na comunidade, banindo, por 
completo, o modelo hospitalocêntrico, que vigorava até então, conforme comentado por Fialho (2014):

O cuidado em saúde mental, conforme proposto pelo ideário da Reforma Psiquiátrica, embasa-se, portanto, nos mesmos princípios que orientam o Sistema Único da Saúde: noção de território, organização da atenção em rede, intersetorialidade, reabilitação psicossocial, interdisciplinaridade, desinstitucionalização, promoção de cidadania e construção da autonomia possível de usuários e familiares. (FIALHO, 2014, p.12).

A Lei 10.216/2001 (BRASIL, 2001) contemplou a assistência aos portadores de transtornos mentais graves e persistentes, de qualquer faixa etária, além dos acometidos pelo uso de substâncias psicoativas. Assim, as crianças e adolescentes portadores de transtornos também foram referidas, quebrando uma prática, que até então vigorava, que era a de só oferecer tratamento para crianças e adolescentes vítimas de abandono (modelo assistencialista, respaldado pela teoria higienista), ou aquelas merecedoras de medidas socioeducativas (COUTO; DELGADO, 2015). Nesse momento histórico, o Estado entrava como ente tutelar, com o objetivo de corrigir os comportamentos desviantes.

Na população infantil, são encontradas altas taxas de prevalência de transtornos mentais. Beltrame e Boarini (2013) informam que a incidência de transtornos mentais entre crianças e adolescentes, em todo mundo, revela uma prevalência na faixa de $10 \%$ a $20 \%$, dos quais, entre $3 \%$ e $4 \%$ necessitam de cuidados intensivos.

Em consonância com a Lei 10.216/2001, foi promulgada, em 27 de dezembro de 2012, a Lei 12.764 (BRASIL, 2012), que institui a Política Nacional de Proteção dos Direitos da Pessoa com Transtornos do Espectro Autista e estabelece diretrizes para sua consecução. Esta lei caracteriza o portador do espectro autista, salientando os seus direitos e os deveres do Estado para com os mesmos, destacando aspectos da assistência, escolarização, proteção, acesso e inclusão no mercado de trabalho.

Este marco legal legitimou a assistência aos autistas na Rede de Atenção de Saúde Mental, portanto, usuários dos serviços de CAPS (Centro de Atenção Psicossocial), definido a partir da portaria 336, de 19 de fevereiro de 2002 (BRASIL, 2002), que versa sobre os locais de atendimentos dos portadores de transtornos graves e persistentes. 
Todavia, em 26 de abril de 2017, foi instituída a Lei 13.438, que obriga que o Sistema Único de Saúde disponibilize protocolo de investigação de risco psíquico para o desenvolvimento psíquico das crianças.

\section{Aspectos subjetivos do Autismo}

O autismo é um transtorno comportamental que, na maioria dos casos, mostra-se, através de limitações que acometem a criança desde a infância. Caracteriza-se pela dificuldade em manter contato social, com padrões de comunicação estereotipados e repetitivos, e, muitas vezes, associado a perdas cognitivas e pouco interesse pela diversidade de objetos que cercam o sujeito, restringindo seu campo exploratório. O autismo é um Transtorno Global do Desenvolvimento e pode se manifestar de diversas formas. Devido a essa diversidade, o Manual Diagnóstico e Estatístico de Transtornos Mentais (DSM - 5), da Associação Americana de Psiquiatria (AMERICAN PSYCHIATRIC ASSOCIATION, 2014), com o objetivo de contemplar as diversas categorias do autismo, considerou o Transtorno do Espectro do Autismo, o que reafirma a peculiaridade de cada sujeito portador dessa síndrome.

No âmbito clínico, deparamo-nos com a dificuldade de chegar a um diagnóstico tão fechado e determinante. Encontrarmos crianças falantes, não falantes, embotadas afetivamente, umas conhecem todas as letras do alfabeto, mas são incapazes de controlar os esfíncteres, outras não falam, mas apontam para qualquer palavra escrita, demonstrando que as leem, enfim, uma diversidade de comportamentos diante da qual só um acompanhamento longitudinal pode garantir um fechamento diagnóstico tão preciso e certeiro:

Uma grande prova da complexidade e da multiplicidade de fatores e aspectos envolvidos no desenvolvimento infantil são, de modo mais explícito, os casos em que a criança não possui qualquer impedimento orgânico detectável, mas não consegue avançar em suas aquisições - por exemplo, tem tudo para andar, mas não anda. Por isso, não espere que um desenvolvimento natural venha a corrigir o que está em atraso ou prejuízo, é necessário intervir a tempo e da forma correta para auxiliá-la em seu crescimento. (FERNANDES et al., 2014, p. 18). 
Essa complexidade na assistência, que perpassa o atendimento às crianças, se mostra mais desafiadora quando da suspeita diagnóstica de um autismo. Além dos aspectos orgânicos, como o desenvolvimento neurológico, mudança na tonicidade, crescimento físico (peso, estatura), desenvolvimento sensorial, aquisição de autonomia e os aspectos emocionais, espera-se que a criança, ao nascer, vá alcançando os marcos de desenvolvimento estabelecidos. Todavia, nem sempre tudo acontece da mesma forma e no mesmo ritmo para todos, principalmente nos aspectos psicológicos, que são inter-relacionados a todos os outros referenciais.

A criança, como um ser em desenvolvimento, é dinâmica e pode apresentar atrasos que, muitas vezes, são compensados por estimulações até da ordem da socialização (por exemplo, é notória a mudança comportamental ao entrar na escola), e obedece à influência daquilo que, muitas vezes, é desconsiderado no universo da organicidade, o aspecto cultural. Ao tratarmos de criança, brincamos como forma de observar sua interação com o mundo, e esse brincar é recheado de traços da cultura na qual ela está inserida. Fernandes et al. (2014), ao falar da "mostração", aquilo que o bebê faz para interagir com o mundo, advertem:

Esses modos de "mostração" podem confundir os profissionais. Por exemplo, recusar o olhar ativamente ou ter um olhar que perpassa o outro não são necessariamente patognomônicos de autismo e nem de risco de evolução para tal. Por isso, necessitamos ter bastante cuidado no momento da detecção precoce de dificuldades no bebê. Sabendo os sinais de risco de evolução para o autismo, devemos estar atentos aos detalhes, tanto para não levantarmos suspeitas infundadas como para não deixarmos passar o diagnóstico de um bebê que está evoluindo para a cristalização da síndrome autística. (FERNANDES et al., 2014, p.22-23).

Diante dos desafios do atendimento à infância, deparamo-nos com a Lei 13.438, sancionada em 26 de abril de 2017 (BRASIL, 2017), a qual altera a Lei 8.069, de 13 de julho de 1990, conhecida como Estatuto da Criança e do Adolescente, para tornar obrigatória:

[...] a aplicação a todas as crianças, nos primeiros dezoito meses de vida, de protocolo ou instrumento construído com a finalidade de facilitar a detecção, em consulta pediátrica de acompanhamento da criança, de risco para seu desenvolvimento psíquico. (BRASIL, 2017, p.1). 


\section{Medicalizar é patologizar: primazia do biologicismo}

Um documento assinado por vários autores adverte para os riscos de uma lei que determina como protocolo pediátrico a aplicação desses instrumentos e os efeitos iatrogênicos advindos dessa ação. Inicialmente, porque destaca uma prática medicalizante e patologizante (PSICANALISTAS PELA DEMOCRACIA, 2017).

A medicalização não é a mera utilização de remédios, medicalizar é olhar a vida sob a ótica da doença, é definir o outro a partir da sua falta, não a partir do seu potencial. Se, para a Psicanálise, somos seres faltantes, e, a partir da falta, nos movemos no mundo, como ser definidos apenas por esse buraco existencial?

Moysés e Collares (2014) advertem para o avanço da medicalização em todas as esferas da vida, propagando o desaparecimento das desigualdades ou transformando em problemas individuais, no plano do biológico:

Com o advento da Medicina moderna, ela se atribui a tarefa de legislar e normatizar o que é saúde e o que é doença, o que é saudável e o que não é. Quase naturalmente, passa a legislar também sobre os critérios para identificar, segregar e silenciar (de diferentes maneiras) os que afrontavam as normas sociais. (MOYSÉS; COLLARES, 2014, p.25).

A aplicação de instrumentos que são incompletos, que desconsideram os elementos culturais, meras respostas objetivas, pode marcar esse sujeito para o resto da vida, inclusive, barrando a potencialidade de desenvolvimento que este poderia alcançar. Moysés e Collares (2014), ao avaliarem o questionário SNAP IV, que pretende diagnosticar o Transtorno de Déficit de Atenção e Hiperatividade, fazem o seguinte questionamento:

Como médicos, psicólogos e fonoaudiólogos podem acreditar e querer fazer todos acreditarem que 18 perguntas possam de fato identificar pessoas com uma doença neurológica ou neuropsiquiátrica? (MOYSÉS; COLLARES, 2014, p.22).

Na prática clínica, verificamos os efeitos de uma comunicação diagnóstica, e como a singularidade de cada caso deve ser respeitada. A depender de como se comunique um diagnóstico, pode selar, para o bem ou para o mal, a vida daquela criança. $O$ efeito de tal ato pode ser perverso e atingir a família, que passa a analisar o comportamento da criança sob a ótica da doença, e a criança, que passa a ser marcada, tatuada com o estigma do portador de 
transtorno mental: "Para muitos pais e famílias, a experiência de ter um filho diagnosticado com uma doença mental pode ser uma desgraça; isto nós devemos dizer" (COSTELLO apud WHITAKER, 2017, p. 225).

Ao tratarmos de crianças com idade tenra, de zero a 18 meses, considerada a primeira infância, esse efeito parece ser mais devastador. Collares et al. (2014), ao tratarem de crianças disléxicas dizem:

Todas as pessoas que passam por avaliação na ABD (Associação Brasileira de Dislexia) são sumariamente transformadas em pacientes. Pode-se identificar aí afinidades com a concepção de justiça vigente nas sociedades monárquicas, fundadas na herança divina para justificar as desigualdades: uma vez suspeito, jamais se retornava à condição de inocente, pois a suspeição representaria uma meia-culpa e uma meia-culpa se igualava à culpa inteira. (COLLARES et al., 2014, p.53).

Whitaker (2017) avalia o aumento do uso de medicações psiquiátricas em crianças e adolescentes. Ele realiza um levantamento histórico de como comportamentos tidos como normais até determinada época se transformam em patológicos e o efeito disso no consumo de medicações. Seu texto retrata, inicialmente, o surgimento do Transtorno do Déficit de Atenção e Hiperatividade (TDAH), o efeito da Ritalina, droga usada para seu tratamento e a não correspondência entre o que é proposto e o que, realmente, é alcançado. Ele continua o capítulo, com um item que nomeia "Criando a criança bipolar", no qual trata como se verificou que crianças sofriam de depressões, e o pulo seguinte para o diagnóstico de bipolaridade na infância.

\section{Considerações finais}

A partir dessas concepções, pode-se inferir o efeito da Lei 13.438 (BASIL, 2017), a partir da sua prática contínua. A aplicação da lei pode gerar o fortalecimento do autismo como doença unicamente orgânica, destacando exclusivamente os aspectos biológicos de uma síndrome complexa, o que implicaria a ampliação do mercado de consumo de medicamentos, além dos efeitos devastadores na solidificação e rotulação diagnóstica para aquele sujeito. 
Especialistas recorrem à clínica ampliada como contraponto à Lei 13.438/2017, redirecionando para intersetorialidade e a construção de planos terapêuticos singulares, que visem à promoção do cuidado em redes, que incluam saúde, educação e direitos sociais, além de entendimento daquela criança no seu âmbito cultural, fortalecendo os laços sociais com a sua família e o seu lugar de pertencimento (PSICANALISTAS PELA DEMOCRACIA, 2017).

A clínica da infância é merecedora de um cuidado especial, tanto em consideração àquele sujeito, muitas vezes, ainda se inserindo no campo da linguagem, que ali se apresenta, levado pela família, conquistando e avançando no seu desenvolvimento, como, também, em relação aos familiares, que, ainda na expectativa do devir do infante, depositam naquele profissional a confiança e expectativa de um saber.

\section{Referências}

AMERICAN PSYCHIATRIC ASSOCIATION. DSM-5: manual diagnóstico e estatístico de transtornos mentais. 5. ed. Porto Alegre: Artmed, 2014.

BELTRAME, M. M.; BOARINI, M.L. Saúde mental e infância: reflexões sobre a demanda escolar de um capsi. Psicologia: ciência e profissão, v. 33, n. 2, p. 336-349, 2013.

BRASIL. Lei 10.216, de 6 de abril de 2001. Dispõe sobre a proteção e os direitos das pessoas portadoras de transtornos mentais e redireciona o modelo assistencial em saúde mental. Presidência da República. Casa Civil. Subchefia para Assuntos Jurídicos. Disponível em:<http://bvsms.saude.gov.br/bvs/saudelegis/gm/2002/prt0336_19_02_2002.html>. Acesso em: 15 nov. 2017.

BRASIL. Lei 12.764, de 27 de dezembro de 2012. Institui a Política Nacional de Proteção dos Direitos da Pessoa com Transtorno do Espectro Autista; e altera o $\$ 3^{\circ}$ do art. 98 da Lei no 8.112, de 11 de dezembro de 1990. Presidência da República. Casa Civil. Subchefia para Assuntos Jurídicos. Disponível em:<http://www.planalto.gov.br/ccivil_03/_ato20112014/2012/lei/l12764.htm>. Acesso em: 24 nov. 2017.

BRASIL. Lei 13.438, de 26 de abril de 2017. Altera a Lei 8.069, de 13 de julho de 1990, para tornar obrigatória a adoção pelo Sistema Único de Saúde (SUS) de protocolo que estabeleça padrões para a avaliação de riscos para o desenvolvimento psíquico das crianças. Presidência da República. Casa Civil. Subchefia para Assuntos Jurídicos. Disponível em:<http://www.planalto.gov.br/ccivil_03/_ato2015-2018/2017/lei/L13438.htm>. Acesso em: 24 nov. 2017.

BRASIL. Portaria 336, de 19 de fevereiro de 2002. Dispõe sobre a organização de serviços comunitários de saúde mental, proteção e os direitos das pessoas portadoras de transtornos mentais e redireciona o modelo assistencial em saúde mental. Ministério da Saúde. 
Gabinete do Ministro. Disponível

em:<http://bvsms.saude.gov.br/bvs/saudelegis/gm/2002/prt0336_19_02_2002.html>.

Acesso em: 15 nov. 2017.

COLLARES, C. A. L. et al. A educação na era dos transtornos. In: VIÉGAS, L. S. et al.

Medicalização da educação e da sociedade: ciência ou mito? Salvador: EDUFBA, 2014, p. $45-65$.

COUTO, M.C.V.; DELGADO, P.G.G. Crianças e adolescentes na agenda política da saúde mental brasileira: inclusão tardia, desafios atuais. PsicClin, Rio de Janeiro, v. 27, n. 1, p. 1740, 2015 .

FERNANDES, C. M. et al. Atenção às crianças e adolescentes com autismo e seus familiares no âmbito da Rede de Atenção Psicossocial. Florianópolis: UNASUS, 2014.

FIALHO, M.B. Fundamentos da atenção à crise e urgência em saúde mental. In: ZEFERINO, M.T. Crise e urgência em saúde mental: fundamentos da atenção à crise e urgência em saúde mental, Florianópolis: UFSC, 2014, p. 11-57.

GOMES, R. O alienista: loucura, poder e ciência. In: ASSIS, M. de. O alienista.Ed. Especial. Rio de Janeiro: Nova Fronteira, 2017.p. 5-27.

MOYSÉS, M. A. A.; COLLARES, C. A. L. Medicalização do comportamento e da aprendizagem: a nova face do obscurantismo. In: VIÉGAS, L. S. et al. Medicalização da educação e da sociedade: ciência ou mito? Salvador: EDUFBA, 2014.p.19-43.

PSICANALISTAS PELA DEMOCRACIA. Sobre a Lei 13.438, de 26/4/2017: riscos e desafios.2017. Disponível em: <http://psicanalisedemocracia.com.br/2017/08/sobre-a-lei-13438-de-26417-riscos-e-desafios/. Acesso em: 23 nov. 2017.

WHITAKER, R. Anatomia de uma epidemia: pílulas mágicas, drogas psiquiátricas e o aumento assombroso da doença mental. Rio de janeiro: Editora Fiocruz, 2017.

\section{Dados da autora}

Suely Maria Costa Lôbo

Mestranda em Políticas Sociais e Cidadania, UCSal, especialista em Psicologia Infantil, Psicóloga da Secretaria Municipal de Saúde, Salvador. Email: suely.lobo@yahoo.com.br

\section{Agradecimentos}

Agradecimentos a Ana Maria Fernandes Pitta pela orientação de pesquisa. 